\title{
Intermediate Adjunction with A-Movement
}

\author{
Uli Sauerland \\ Universität Tübingen
}

It's widely assumed—often tacitly—-that A-movement doesn't move through intermediate positions where it doesn't seem to check features (e.g. Baltin 2001). Chomsky (2001), however, proposes that all movement from inside the complement of $\mathrm{v}$ to a position above vP must pass through an intermediate position in the edge of vP. Within Chomsky's proposal, this follows from the assumption that $\mathrm{vP}$ is a Phase. Fox (1999) and Nissenbaum (2000) argue on independent grounds that A-bar movement across vP must leave an intermediate trace in vP. In this squib, I give one argument in favor of intermediate adjunction to $\mathrm{vP}$ in the case of A-movement across vP.

A well-studied case of A-movement is raising in English. With Chomsky (1995) and others, I assume that raising is movement of the subject from a position in the infinitival complement to the matrix Spec(TP) position to satisfy the EPP. This is illustrated in (1).

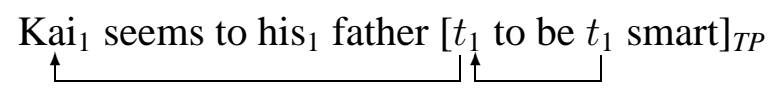

Secondly, consider the interpretation of (2), where the universal quantifier is in the scope of negation. This interpretation can be paraphrased as Not every child is smart. It

Draft

printed on August 26, 2001 
requires a special intonation with a rise on every and a fall on isn't (Jackendoff 1972, Büring 1997), but is definitely a possible interpretation of (2). [Every child $]_{1}$ isn't $t_{1}$ smart.

I assume with McCloskey (1997) that this interpretation is derived by total reconstruction of the subject to a position lower than negation. Furthermore, I assume that the mechanism responsible for total reconstruction is LF-deletion applying within the copy theory of movement as in (Hornstein 1995) (though my argument below is also compatible with Sauerland and Elbourne's (2000) PF-movement account of total reconstruction). Specifically, I assume that the pronounced copy of the subject in (2) is deleted, while a lower copy is interpreted. This is sketched in (3).

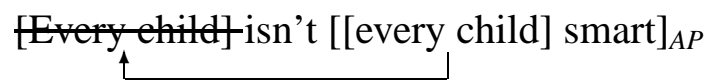

Now, consider the example in (4). With the same intonation noted for (2), this example also allows an interpretation where negation takes scope over the subject. At the same time, the quantifer every child can bind the pronoun his. This interpretation can be paraphrased as: It's not the case for every child that it seems to his father to be smart.

(4) Every child ${ }_{1}$ doesn't seem to his ${ }_{1}$ father [ $t_{1}$ to be smart.] 
Similarly, the examples in (5) also allow interpretations where the subject takes scope below negation but binds a pronoun in the matrix clause.
a. Every participant ${ }_{1}$ didn't seem to his ${ }_{1}$ coach $t_{1}$ to be winning.
b. All linguists ${ }_{1}$ didn't seem to their ${ }_{1}$ employer $t_{1}$ to be ingenious.

Because of the particular interpretation noted, I assume that example (4) and structurally similar examples allow an LF-structure where the subject quantifier is lower than negation, but is not in the embedded clause. The latter follows from the fact that the quantifier binds a variable in the object of seem, and therefore must be in a position that ccommands the object of seem. Such a structure is sketched in (6). 
(6)

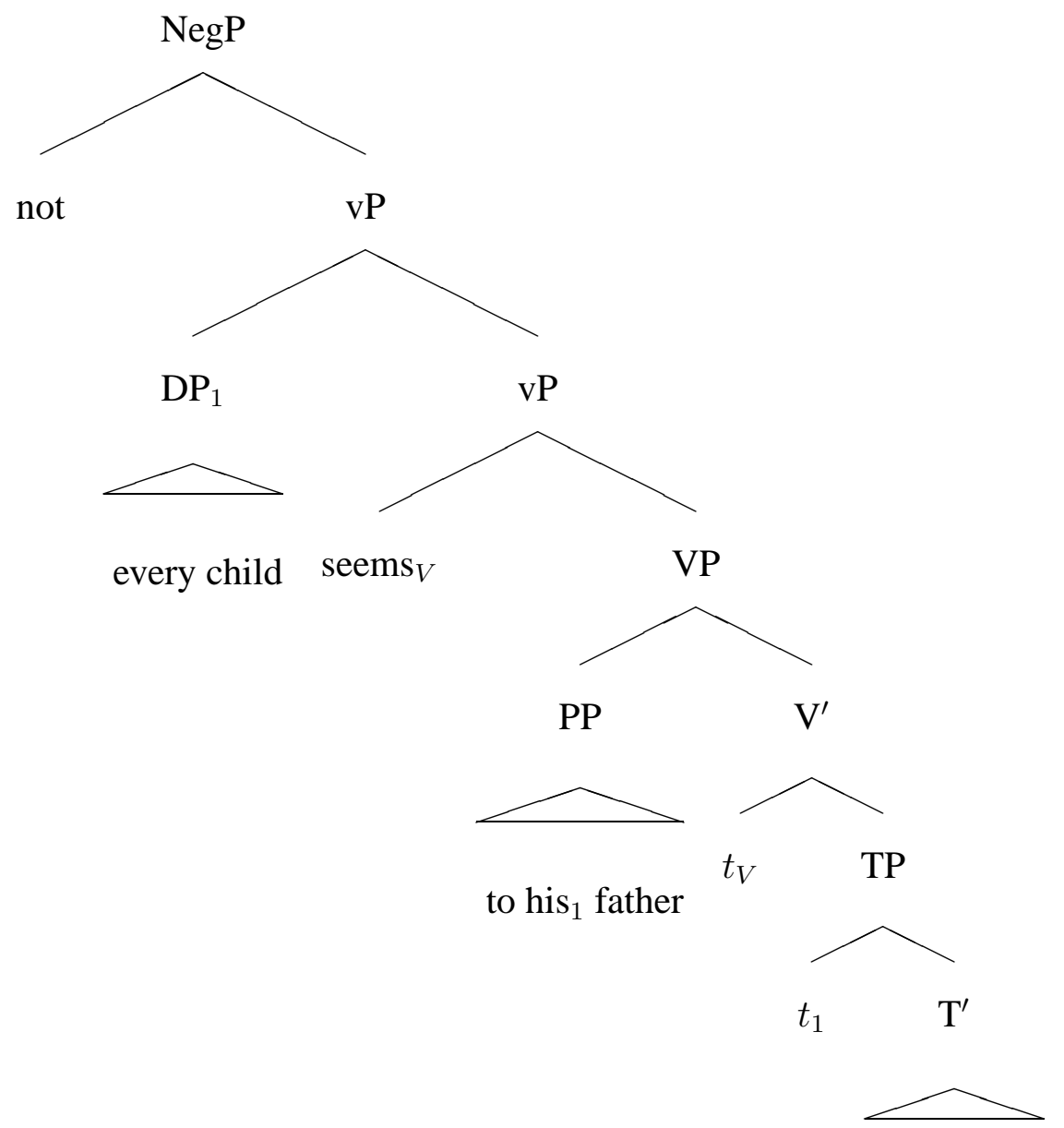

to be smart

How could structure (6) have been derived? It's clear that the pronounced copy of every child in (4) must be deleted to derive representation (6). Could the lower copy of every child move to a position taking scope above seems by quantifier raising? There are two problems with such a derivation of (6). For one, weak crossover should block binding of the pronoun his in such a derivation. Furthermore, Lebeaux (1995) argues that quantifier raising is impossible out of a raising infinitival. As shows, this assumption explains why 
(7) doesn't allow an interpretation where the embedded object takes scope over the matrix subject with the binding relation indicated.

[Two women] $]_{1}$ seemed to each other ${ }_{1}$ to $t_{1}$ be dancing with every senator.

If all the assumptions I adopted up to now are correct, that leaves one plausible derivation for (6).: A-movement of every child from the embedded Spec(TP) to the matrix Spec(TP) creates an intermediate copy of every child in a vP adjoined position below negation. If this intermediate copy is interpreted, while the others are deleted or converted into traces the representation in (6) is the result.

Given the results of Fox (1999) and Nissenbaum (2000) concerning intermediate traces of A-bar movement, it is probably the simplest assumption that A-movement behaves the same way. If my argument is correct, this assumption is corroborated empirically.

\section{References}

Baltin, MARK. 2001. A-movements. In The Handbook of Contemporary Syntactic Theory, ed. by M. Baltin and C. Collins, 226-254. Blackwell.

BÜRING, DANIEL. 1997. The Meaning of Topic and Focus: The 59th Street Bridge Accent. London: Routledge.

Chomsky, NoAm. 1995. The Minimalist Program. Cambridge, Mass.: MIT Press.

—. 2001. Derivation by phase. In A Life in Language, ed. by M. Kenstowicz. Cambridge, Mass.: MIT Press.

FOX, DANNY. 1999. Reconstruction, variable binding and the interpretation of chains. Linguistic Inquiry 30.157-196.

Hornstein, Norbert. 1995. The Grammar of Logical From: From GB to Minimalism. Cambridge, Mass.: Blackwell.

JACKENDOFF, RAY. 1972. Semantic Interpretation in Generative Grammar. Cambridge, Mass.: MIT Press. 
LEBEAUX, DAVID. 1995. Where does the binding theory apply? In University of Maryland Working Papers in Linguistics 3, 63-88. College Park: University of Maryland.

MCCLOSKEY, JAMES. 1997. Subjecthood and subject positions. In Elements of Grammar: Handbook in Generative Syntax, ed. by L. Haegeman, 197-236. Dordrecht, Netherlands: Kluwer.

Nissenbaum, Jon. 2000. Investigations of Covert Phrase Movement. Ph.D. dissertation, Massachusetts Institute of Technology, Cambridge, Mass.

Sauerland, Uli, and PAul Elbourne. 2000. Total reconstruction, PF-movement and derivational order. Linguistic Inquiry . (to appear). 